\title{
O USO DE SOFTWARES NA PRÁTICA PROFISSIONAL DO PROFESSOR DE MATEMÁTICA*
}

\author{
The use of software in the professional practice \\ of Mathematics teachers
}

\author{
Claudinei de Camargo Sant'Ana ${ }^{1}$. Rúbia Barcelos Amaral ${ }^{2}$. \\ Marcelo de Carvalho Borba ${ }^{3}$
}

Resumo: Este artigo apresenta uma pesquisa que é resultado de cursos online de formação continuada de professores, concebidos a partir de uma parceria entre a UNESP e uma rede nacional de escolas de Ensino Básico. Os cursos buscavam familiarizar os professores de Matemática com os recursos da tecnologia informática, especificamente dois softwares, o Geometricks e o Winplot, no que diz respeito à utilização destes na sala de aula. Após alguns anos da realização dos mesmos, na pesquisa aqui descrita, objetivamos identificar "se e como" os softwares foram incorporados à prática profissional, em um cenário em que os professores podem contar com laboratórios, formação continuada e suporte técnico. A partir de entrevistas online, pudemos mapear as diferentes escolhas dos professores: não-uso; uso de forma semelhante (ou não) à vivenciada no curso online, e o uso interdisciplinar, mostrando variadas formas pelas quais os professores "retraduziram" o curso para sua prática.

Palavras-chave: Formação continuada de professores. Ensino a distância. Software educacional. Educação matemática. Tecnologia educacional.

Abstract: This study is the result of on-line continuing education courses for teachers taught through a partnership between UNESP and a national network of basic education schools. The courses aimed to familiarize mathematics teachers with information technology resources, specifically two software programs, Geometricks and Winplot, and their potential use in the classroom. After having taught the course for several years, we sought to identify "if and how" the software programs were being incorporated into the professional practice of teachers who have access to computer laboratories, continuing education, and technical support. Based on on-line interviews, we were able to map the different choices made by the teachers: non-use; utilization in a manner similar (or not) to their experience in the on-line course; and interdisciplinary use. These teachers "re-translated" their experience in the on-line course for application in their own practice in diverse ways.

Keywords: Continued teacher education. Distance education. Educational software. Mathematics education. Educational technology.

\footnotetext{
* Pesquisa realizada com apoio financeiro do Conselho Nacional de Desenvolvimento Científico e Tecnológico (CNPq), Processo 504590/2009-0.

${ }^{1}$ Departamento de Ciências Exatas, Universidade Estadual do Sudoeste da Bahia. Estrada do Bem-querer, km 04. Vitória da Conquista, BA, Brasil.45.083-900. claudinei@ccsantana.com

${ }^{2}$ Faculdade de Ciências Aplicadas, Universidade Estadual de Campinas. Limeira, SP, Brasil.

${ }^{3}$ Departamento de Matemática, Universidade Estadual Paulista “Júlio de Mesquita Filho" (Unesp), campus de Rio Claro, SP, Brasil.
} 


\section{Introdução}

Há cerca de dez anos se iniciaram as pesquisas em Educação Matemática online no país. Em um primeiro momento, as pesquisas se concentravam sobre cursos específicos online e suas possibilidades. Gracias (2003), em trabalho pioneiro, analisou, por exemplo, como professores vivenciaram um curso de Educação Matemática a distância oferecido no ano de 2000. Em momento posterior, Santos (2006) e Bairral (2007) analisaram como conteúdos específicos de Geometria podem ser apreendidos e ensinados online.

Pesquisas em Educação online foram desenvolvidas em grande número na segunda metade da década passada, em franco contraste com a primeira metade. As pesquisas do Grupo de Pesquisa em Informática, outras Mídias e Educação Matemática (GPIMEM) 4 na área de Educação a Distância, entendida aqui como uma modalidade de Educação que ocorre, total ou parcialmente, em diferentes espaços de tempo e/ou geográficos, têm sido realizadas desde 2000. Em 2004, o grupo estabeleceu uma parceria com uma rede nacional de escolas de Educação Básica que proporcionou o desenvolvimento de cursos online para professores de Matemática. Autores como Borba, Maltempi e Malheiros (2005), Gadanidis e Geiger (2010), Gadanidis, Namukasa e Moghaddam (2008) e Litto e Formiga (2009) apontam para a importância e a especificidade do desenvolvimento deste tipo de ação educativa.

O ensino oferecido por essa rede de escolas é gratuito e prioriza o atendimento a alunos menos favorecidos economicamente. Para tanto, em sua maioria, suas escolas situamse na periferia das cidades. São quarenta escolas distribuídas em todo o país, sendo ao menos uma unidade em cada estado do território nacional. Após a realização dos cursos, observamos que a maioria dos estados do país foi representada com a participação de docentes.

Para desenvolver um trabalho com conteúdos de Geometria, foram desenvolvidas três edições do "Geometria com Geometricks" semelhante foi realizado em quatro edições, com foco no estudo de Funções: "Funções com Winplot". Para contemplar todos os interessados, os cursos foram realizados de 2004 até 2008, e envolveram mais de cem docentes, sendo que vários fizeram os dois cursos.

Os cursos foram desenvolvidos por meio de encontros virtuais síncronos, realizados aos sábados, com duração de duas horas, por videoconferência. Nesses encontros se discutiam soluções para problemas postados com antecedência no sítio do curso, assim como o conteúdo pedagógico (SHULMAN, 1986) relacionado ao uso de softwares de Matemática na sala de aula. Na sequência havia acompanhamento assíncrono, visando o apoio às dúvidas dos docentes e a preparação do encontro síncrono seguinte.

Neste cenário, o GPIMEM já desenvolveu trabalhos de pesquisa para saber como os professores exploram Matemática em ambiente online (ZULATTO, 2007; BORBA, MALHEIROS; AMARAL, 2011) e como os docentes que ministram o curso também aprendem Matemática com essa experiência (BORBA; ZULAT'TO, 2010). No presente artigo relatamos uma

\footnotetext{
${ }^{4}$ Endereço eletrônico: <http://www.rc.unesp.br/gpimem>.

${ }^{5}$ Disponível em: < http://www.geo-metricks.com>. Acesso em: 04 abr. 2010.

${ }^{6}$ Disponível em: <http://math.exeter.edu/rparris/winplot.html>. Acesso em: 04 abr. 2010. 
nova fase nos estudos do grupo, na qual queremos compreender o uso dos softwares nas escolas hoje, passados mais de três anos do último curso ministrado. Para tanto, identificamos e caracterizamos se houve continuidade, após os cursos, na utilização dos softwares dentro da escola, e qual a maneira desenvolvida pelos professores na prática de sala de aula.

\section{Metodologia}

O trabalho aqui apresentado foi desenvolvido segundo a abordagem qualitativa de pesquisa. Como afirmam Bogdan e Biklen (1994, p. 209), os estudos dessa natureza "devem revelar maior preocupação pelo processo e significado e não pelas suas causas e efeitos". Nesse sentido, nosso interesse estava centrado em analisar o modo de incorporação (ou não) de softwares como Geometricks e Winplot na prática profissional dos professores (PONTE, 2008), e não em seus resultados ou produtos, o que contempla uma das características centrais da pesquisa qualitativa, segundo Denzin e Lincoln (2000) e Vidich e Lyman (2000).

A utilização de múltiplos procedimentos de coleta de dados favorece a confiabilidade da pesquisa, e a análise a partir dessa multiplicidade é denominada triangulação, processo que pode auxiliar na compreensão do fenômeno pesquisado. A triangulação "não é uma ferramenta ou estratégia de validação, mas uma alternativa para a validação" (LINCOLN; GUBA, 1985, p. 5). Além disso, a triangulação pode aumentar a credibilidade de uma pesquisa que adota a abordagem qualitativa, [credibilidade essa] entendida como a plausibilidade, para os sujeitos envolvidos, dos resultados e interpretações feitas pelo pesquisador (ARAÚJO; BORBA, 2004, p. 35).

Com essa preocupação, buscamos utilizar diferentes fontes de dados, que foram obtidos, em um primeiro momento, a partir dos relatórios finais dos cursos e de questionário encaminhado via e-mail aos docentes que cursaram, pelo menos, um dos cursos. A coordenação pedagógica da rede de escolas colaborou com a pesquisa oferecendo informações atuais sobre o vínculo dos professores e confirmando o endereço eletrônico de quem ainda permanecia lecionando nas escolas da rede. E, em um segundo momento, entrevistas online com os professores compuseram os dados da pesquisa.

\section{Coleta dos dados}

Iniciamos a presente pesquisa identificando os docentes que participaram ao menos de uma versão dos cursos oferecidos, e que ainda permaneciam vinculados à escola. Na sequência, realizamos contatos via e-mail questionando sobre a possibilidade de participação dos mesmos na pesquisa. Neste momento, foi solicitado que respondessem a um breve questionário, contendo sete perguntas relacionadas: à participação nos cursos; à utilização dos softwares durante os anos de 2008 e 2009 (nossa intenção era identificar quais eram os docentes que ainda estavam utilizando os softwares em sala de aula); e à disponibilidade de participar de uma entrevista. $\mathrm{Na}$ apresentação que acompanhava o questionário, explicávamos se tratar de uma pesquisa com o intuito de analisar as contribuições dos cursos supracitados, bem como a incorporação dos softwares nas aulas de Matemática.

Esse questionário era composto das seguintes questões: 
a) Você participou do curso "Geometria com Geometricks"? Sim ( ) Não ( )

b) Você participou do curso "Funções com Winplot"? Sim ( ) Não ( )

c) Em 2008/2009 você usou algum software em suas aulas? Sim ( ) Não ( ); Se sim, qual(is)?

d) Mais do que cinco vezes? $\operatorname{Sim}($ ) Não ( )

e) No caso de ter usado algum software, você tem disponibilidade para contar sua experiência (por chat ou videoconferência) num momento a ser agendado? Sim ( ) Não ( )

f) No caso de não ter usado nenhum software, tem disponibilidade para contar por que fez essa escolha (quais fatores influenciaram nessa decisão) num momento a ser agendado? Sim ( ) Não ( )

Foram enviadas, aproximadamente, duzentas e cinquenta mensagens com os questionários anexados, mas devido ao fato de que poucas respostas foram recebidas brevemente, foi necessário enviar o chamado mais de uma vez. Dos professores que realizaram os cursos, apenas 74 encontravam-se trabalhando nas escolas da rede educacional em estudo e, destes, recebemos retorno de 56 questionários, cuja localidade e quantidade seguem a seguinte relação: Aparecida de Goiânia/GO (um), Bagé/RS (dois), Boa Vista/MA (um), Cacoal/RO (um), Caucaia/CE (três), Ceilândia/DF (cinco), Gravataí/RS (um), Irecê/BA (dois), Itajubá/MG (dois), Jaboatão/PE (um), Conceição do Araguaia/PA (três), João Pessoa/PB (um), Laguna/ SC (um), Macapá/AP (dois), Natal/RN (três), Osasco/SP (dez), Paragominas/PA (dois), Registro/SP (um), Rio Branco/AC (dois), Rio de Janeiro/RJ (cinco), Salvador/BA (um), São João Del Rei/MG (dois), São Luis/MA (um), Teresina/PI (um), Marília/SP (dois).

Realizamos novo contato para o agendamento das entrevistas, privilegiando os horários e dias escolhidos por eles. Elas ocorreram nos mais diversos horários e dias da semana, inclusive aos sábados e feriados. Entendemos que existe, nesse fato, indícios de que a carga horária de trabalho dos professores é alta. Talvez esse seja um forte motivo de termos conseguido agendar e realizar apenas 14 entrevistas em um conjunto de 48 professores que se disponibilizaram para tal. O roteiro para a entrevista, semiestruturada (LINCOLN; GUBA, 1985), privilegiou os seguintes eixos: a) utilização do software: metodologia, frequência, conteúdos, atividades, reflexos na prática; e b) condições para a utilização: apoio institucional, técnico, tempo adequado. Os docentes entrevistados pertencem aos seguintes estados do Brasil: Amapá, Goiás, Rio de Janeiro, Rio Grande do Sul, Paraíba, Pernambuco e São Paulo.

Algumas das entrevistas realizadas oralmente foram gravadas, utilizando-se o software Camtasia ${ }^{7}$, e, em outras, valemo-nos do gravador padrão de som. Aquelas realizadas utilizando o chat do MSN foram arquivadas automaticamente. Cabe ressaltar que optamos por apresentar as declarações dos entrevistados com pseudônimos, tendo em vista preservar a identidade dos declarantes. Data e tempo decorrido da gravação fazem parte das transcrições para situar cronologicamente o processo das entrevistas. Assim, uma transcrição na qual constem os dados “(21/06/2010 10:30)", significa que a entrevista foi realizada nessa data e que a fala ocorreu com dez minutos e trinta segundos do seu início.

\footnotetext{
${ }^{7}$ Software que grava som e imagem das ações realizadas na tela do computador. Disponível em: <http:// www.techsmith.com>. Acesso em: 25 maio 2010.
} 
O uso de softwares na prática profissional ...

A seguir, apresentaremos a reflexão sobre os dados coletados e os aspectos que julgamos relevantes no que se refere à análise da incorporação (ou não) dos softwares Geometricks e Winplot na prática profissional dos professores.

\section{Contexto dos cursos online}

A rede de ensino envolvida neste estudo proporciona aos seus professores, regularmente, cursos de formação continuada, muitos deles se valendo dos recursos da Educação a Distância online.

Ao iniciarmos nossa pesquisa, recebemos da coordenação pedagógica do conjunto de escolas a seguinte tabela com informações sobre os cursos (Tabela 1).

Tabela 1. Informações sobre os cursos

\begin{tabular}{ccccccc}
\hline & \multicolumn{2}{c}{ Evasão } & & \multicolumn{2}{c}{ Total de cursistas } & \\
\cline { 2 - 3 } Ano & Geometria com Geometricks & Funções com Winplot & & Inscritos & Concluintes & Turmas \\
\hline 2004 & $15 \%$ & $4 \%$ & $3,5 \%$ & 27 & 23 & 1 \\
2005 & $12 \%$ & $28,5 \%$ & & 50 & 48 & 2 \\
2006 & & & 28 & 27 & 1 \\
2007 & & & & & 15 & 1 \\
2008 & & &
\end{tabular}

Fonte: Elaborado pelos autores.

Podemos observar, conforme consta na Tabela 1, que a participação dos professores nos cursos apresenta índices de evasão que chamam a atenção, pois estes se mantiveram menores ou iguais a $15 \% \mathrm{em}$ todos os cursos, exceto o último. As seis primeiras versões do curso foram ministradas por dois docentes vinculados ao GPIMEM da Unesp ${ }^{8}$.

Durante o desenvolvimento dos cursos, percebeu-se que alguns docentes estavam se destacando nas ações e interações e, com o propósito de oportunizar o desenvolvimento e continuidade da formação dos professores, alguns deles foram preparados para serem tutores em edições futuras do curso (BORBA; AMARAL, 2011). Dessa maneira, a última versão do curso "Winplot-2008" foi liderada por três tutores, que eram docentes formados no decorrer dos cursos anteriores a este. Não dispomos, no entanto, de informações sobre qual pode ser a relação entre o índice de evasão da última turma com o fato de o curso ter sido ministrado pelos tutores. De todo modo, no geral, o índice de evasão dos cursos pode ser considerado baixo, quando comparado com outras experiências online, como mencionam os trabalhos de

\footnotetext{
${ }^{8}$ Os cursos foram ministrados pelos dois últimos autores deste artigo. O terceiro autor já era docente da Unesp, e a segunda era professora em cursos presenciais de instituições particulares e participava, regularmente, de atividades junto ao GPIMEM, sediado na Unesp.
} 
Sant'Ana, C. C.; Amaral, R. B.; Borba, M. C.

Maia, Meirelles e Pela (2004), Bastos e Silva (2009), Favero e Franco (2006) e Santos e Oliveira Neto (2009). Cabe ressaltar que a adaptação ao curso pode ter se constituído fator importante neste índice, pois, no desenvolvimento do mesmo, levou-se em consideração a especificidade de organização que um curso com suporte midiático demanda (BAIRRAL, 2003; KENSKI, 2005-2006).

\section{Opção pelo software e a utilização durante os cursos}

Autores como Zulatto (2002), Clark-Wilson (2009), Miranda e Laudares (2007) e Carneiro e Passos (2009) discutem a importância da utilização de softwares de geometria dinâmica no contexto da aprendizagem matemática. Na mesma direção, Borba (1993), Borba (1995) e Benedetti (2003) abordam as potencialidades de softwares de funções. Essas questões foram também debatidas no curso e houve incentivo constante para que os professores iniciassem práticas de incorporação dessas tecnologias em suas aulas, contando com o apoio do grupo. Esse incentivo gerou efetivo impacto, de modo que, segundo os questionários e as entrevistas, a maioria dos professores, durante e logo após os cursos, fez uso dos softwares em suas aulas. Observamos que, dos docentes que realizaram o curso e responderam o questionário da pesquisa (no total de 48 docentes), 64\% fizeram uso dos softwares em suas aulas de Matemática, no período compreendido entre os anos de 2008 e 2009.

Os dados indicam que $35 \%$ dos docentes que responderam o questionário realizaram o curso de Geometricks, e 65\%, o de Winplot. Também relataram que a maior utilização foi do Winplot, e Mauro explica que isso se deve ao "fato de ser um software onde os alunos têm uma acessibilidade maior, pois está na internet e é free!". Como também por ser um software de fácil manuseio $(16 / 6 / 2010,11: 51)$.

Por outro lado, nem sempre os docentes estão dispostos ou possuem condições de incorporar as tecnologias da informação e comunicação (TIC) (CANNONE; ROBAYNA; MEDINA, 2008; PENTEADO, 2000). Este fato também pode ser verificado neste estudo. Como exemplo, podemos mencionar a professora Lilian, que afirma que dispor de tempo, por vezes, dificulta a incorporação das TIC nas aulas, pois sua carga horária não possibilita a dedicação necessária: "trabalho já há alguns anos em duas redes de ensino, portanto as horas para preparação de materiais de aulas acabam sendo comprometidas” (11/05/2010, 05:24). Ela foi a única participante que concedeu entrevista que afirmou não ter utilizado o software.

Para que os professores concretizem mudanças em sua prática profissional, é necessária a transposição de diversas dificuldades, e as questões particulares fazem parte dessa relação (REZENDE; LOPES; EGG, 2004). Sabemos que há outros professores, como Lilian, que não conseguem dispor de tempo para vivenciar mudanças ou não acham relevante o uso de software em sala de aula. Podemos cogitar, inclusive, que alguns professores podem não ter efetivamente cedido entrevista para nós por não quererem expor essa dificuldade em incorporar as tecnologias em suas aulas, o que contraria o incentivo da escola onde trabalham. Com

\footnotetext{
9 "Software livre" se refere à liberdade de os usuários executarem, copiarem, distribuírem, estudarem, modificarem e aperfeiçoarem o software. Maiores informações em: < http://www.gnu.org/philosophy/freesw.pt-br.html>. Acesso em: 20 jul. 2010.
} 
O uso de softwares na prática profissional ...

efeito, vale salientar que a simples incorporação da tecnologia no ambiente educacional não garante a modificação na prática pedagógica (NASCIMENTO; MONTEIRO, 2007).

\section{Incorporação do software na prática}

Dos 56 professores que responderam ao questionário, 32 afirmaram ter utilizado o software mais do que cinco vezes. Todos os que aceitaram ser entrevistados afirmaram ter utilizado mais do que cinco vezes. Estes dados quantitativos servem para dar um panorama geral. Mas como foram utilizados? Eles reproduziram o que vivenciaram no curso (ou o que pensamos que eles vivenciaram no curso), trilharam caminhos distintos ou mesclaram inovações com o vivenciado no curso? Respostas mais precisas precisam ser analisadas baseadas nos dados qualitativos, característica central desta pesquisa.

$\mathrm{Na}$ descrição da utilização dos softwares, feita através de entrevistas, os professores relataram algumas maneiras pelas quais desenvolveram as ações em sala de aula. O procedimento adotado, na maioria dos relatos, seguiu os seguintes passos: apresentação do software para os alunos e, posteriormente, a utilização dos mesmos para o estudo do conteúdo trabalhado naquele momento pelo docente.

$\mathrm{Na}$ prática de sala de aula, existe a necessidade do conhecimento específico relacionado com as características de cada software (KENSKI, 2007), e também sabemos que "cada aula se configura como um local, um momento, potencialmente favorável a aprendizagens para o professor" (GONÇALVES JÚNIOR; BURIASCO, 2006, p. 104). Observamos que muitos professores usaram o material estudado no curso com seus alunos. Podemos considerar essa uma prática natural, visto que as atividades tinham o formato adequado para aulas com os softwares, e, depois de muitas discussões, acreditamos que os professores sentiam que tinham o domínio/segurança no que tange aos conteúdos, bem como no seu desenvolvimento com os softwares. O que notamos, no entanto, é que não seguiram a proposta pedagógica adotada no curso, onde se pretende conhecer o software fazendo uma atividade matemática. Os professores relataram que iniciavam as experiências apresentando o software, suas ferramentas e menus etc., como descreve a professora Eliete: "fiz uma atividade para os alunos conhecerem o programa, os seus comandos... Nessa atividade eles poderiam explorar livremente para comparar as relações entre as funções e os gráficos e depois utilizamos algumas das atividades iniciais do curso" (16/05/2010, 12:03). Em nossos cursos online nós também fazíamos atividades de familiarização, mas em uma proporção bem menor do que a relatada por Eliete.

É natural que os docentes busquem satisfazer seus anseios e necessidades e que queiram conhecer saídas para isso, mas precisam se familiarizar com o que lhes é apresentado. O conhecimento do software é condição fundamental para viabilizar as novas posturas por parte dos professores, e a construção de seus próprios caminhos (BAIRRAL, 2007; GABINI; DINIZ, 2009). Para Nóvoa (1995, p. 27), a formação tem papel importante para que as mudanças efetivamente ocorram, pois afirma que ela pode estimular o desenvolvimento dos professores, "no quadro de uma autonomia contextualizada da profissão docente" e, ademais, "a formação docente deve ser concebida como um dos componentes da mudança, em conexão estreita com outros setores e áreas de intervenção, e não como uma espécie de condição prévia de mudança” (NÓVOA, 1995, p.27). Com essa preocupação, havia o estímulo para que 
os professores começassem a utilizar os softwares no decorrer dos cursos, de modo a propiciar uma nova vivência em paralelo à formação.

Essa abordagem parece ter gerado segurança nos professores, que foram incorporando as TIC gradativamente; e essa mudança também se reflete progressivamente nas atividades em sala de aula, como relata a professora Odila: "levo os alunos para um primeiro contato, eu dou uma coisinha mais simples e lá eu dou o direcionamento da atividade e por último dou uma proposta pra eles tentarem fazer" (21/06/2010 10:30 0 idem). Odila parece preferir usar um caminho gradual, introduzindo o software aos poucos, ao invés de pôr os alunos em contato com problemas desafiadores.

Diversas formas de mudança na prática e incorporação das TIC ocorreram, como aquela vivenciada pelo professor Anderson, que relata o desenvolvimento de atividades em duplas ou em trios, e realização da explicação inicial utilizando o software projetado em uma tela. Para ele, essa ação permite um acompanhamento melhor por parte da classe toda. Outro procedimento relacionado às ações criadas pelos professores foi descrito pelo professor Mauro, quando narra a organização prática das atividades, pois estabelece

"uma sequência didática criada, mostrando os passos das etapas a serem construídas. Inicialmente, sugeria uma função e pedia que construíssem os gráficos. Em seguida, alterava tanto os sinais como os coeficientes e pedia que realizassem observações sobre o que viram, ou seja, o comportamento da função”. (16/6/2010, 12:08)

Isso ilustra que o professor procura meios para se adequar e, também, desenvolver a sua prática frente ao novo, neste caso, a inserção das TIC na sala de aula.

Apareceram também algumas variações, como a apresentada por Lucas:

"No primeiro momento o trabalho é feito somente no caderno. Após esta etapa, os alunos têm o momento de conhecer as funções do software. Levo para sala um PCTV ${ }^{10}$, e eles acompanham anotando as informações básicas das funções”. (29/05/2010, 01:48)

Vale ressaltar que Lucas trabalha com Ensino Médio e profissionalizante, trazendo, para suas aulas, uma preocupação com a formação do cidadão crítico pela Matemática, conforme revelado em outras partes de sua entrevista. Ele considera que propiciar experiências com as TIC é alfabetizar tecnologicamente os alunos, auxiliando os alunos a dominarem essa tecnologia e utilizá-la em sua vida profissional de técnico. Essa postura está em consonância com o olhar do educador matemático analisado por Fiorentini e Lorenzato (2006, p. 3). Para eles, o educador matemático

[...] tende a conceber a Matemática como um meio ou instrumento importante à formação intelectual e social de crianças, jovens e adultos

${ }^{10}$ Computador com funções de TV. 
O uso de softwares na prática profissional ...

e também do professor de Matemática do ensino fundamental e médio e, por isso, tenta promover uma educação pela Matemática.

Dessa forma, "o educador matemático, na relação entre a Educação e Matemática, tende a colocar a Matemática a serviço da Educação, priorizando, portanto, essa última, mas sem estabelecer uma dicotomia entre eles" (FIORENTINI; LORENZATO, 2006, p. 3).

Ressaltamos, ainda, que é comum a precaução, por parte dos professores, no momento de se realizar a troca de uma aula expositiva - que, na maioria das vezes, é considerada, tradicionalmente, eficaz - por uma aula onde o processo mais participativo do estudante é requerido. Talvez esta seja fruto da pressão exercida pela reconstrução contínua de qualificações e competências (MIRANDA; LAUDARES, 2007).

Observamos que os docentes, no desenvolvimento do trabalho, na prática com as TIC, descrevem uma trajetória semelhante às ações decorrentes das pesquisas em Educação Matemática (FIORENTINI; LORENZATO, 2006), trilhando caminhos que se alternam entre o aprendizado e questões de natureza pragmática, mas voltados para a melhoria do trabalho docente.

\section{Conteúdos, atividades e frequência de utilização}

Diversos foram os conteúdos citados pelos docentes no desenvolvimento de suas aulas com a utilização dos softwares, como, por exemplo, o professor Anderson (10/05/2010, 03:58), que relaciona os tópicos com os quais desenvolve aulas com o software Winplot:

" $1^{\circ}$ - noções básicas das dimensões; $2^{\circ}$ para que serve o software; $3^{\circ}$ onde se usa o software; $4^{\circ}$ funções; $5^{\circ}$ sistemas lineares de duas equações, plano cartesiano, abscissas, eixos bissetrizes, ordenadas; $6^{\circ}$ exponencial e log; identificar gráfico de exponencial crescente ou decrescente, reconhecer gráficos de funções periódicas seno, cosseno é muito legal, interseção de retas lineares, ou de funções de diferentes graus".

A professora Nair apresenta a maneira pela qual se valeu dos softwares: "No $8^{\circ}$ ano usei o Geometricks no estudo da soma dos ângulos internos de polígonos, e o Winplot no estudo de funções no $1^{\circ}$ e $2^{\circ}$ anos do Ensino Médio" (28/05/2010, 12:00). Já para o professor Mauro, a utilização dos softwares propicia o surgimento de discussões baseadas na simulação de situações, facilitando a busca de soluções para as questões e desafios propostos.

Outra professora descreve o trabalho desenvolvido no Ensino Médio: "Fizemos toda revisão de função de $2^{\circ}$ grau e exponencial. Foram 2 aulas. Utilizei as idéias do curso... mas a discussão é outra... o foco estava no conceito e não no programa"; e, no que tange ao desenvolvimento das atividades, ela acrescenta: "Iniciamos a discussão com uma função y $=\mathrm{ax}^{2}+$ $\mathrm{bx}+\mathrm{c}$ genérica... eles poderiam entrar com os coeficientes... traziam conhecimento para discutir os movimentos... trabalhamos com uma única imagem (canhão) para que todos pudessem participar" (Roseli, 20/05/2010, 2:14). 
Os docentes exemplificaram algumas maneiras de utilização dos softwares em sala de aula. Nair (28/05/2010, 15:03) diz: "Usei com maior frequência no Ensino médio, através do estudo das funções, que permite o uso do Winplot (Função polinomial do $1^{\circ}$ e $2^{\circ}$ grau, função exponencial, logarítmica, função seno, cosseno são algumas)". Mauro descreve como utilizou o software Geometricks: "Eu só trabalho com as turmas da $1^{\text {a }}$ série do ensino médio, logo o momento de construção foi na parte de construção de figuras poligonais, tipo triângulos, quadrados, losango e etc". E quanto ao uso do Winplot, acrescenta que utilizou "na construção das funções: afim, linear e constante como também do segundo grau" (16/6/2010,12:03).

Observamos ainda que houve socialização e discussão dos saberes produzidos, e que este é um fator que fortalece a importância de que as ações pedagógicas sejam desenvolvidas nas escolas pelos professores (CARBONELL, 2002; TARDIF, 2002). Quando questionamos sobre a utilização das atividades desenvolvidas no curso ou a preparação de novas atividades, os docentes responderam que fizeram as duas coisas, criaram e também aproveitaram as atividades desenvolvidas nos cursos, como já mencionamos. Um fator importante apresentado foi a socialização dos trabalhos durante o curso: "Já utilizei as que montamos e compartilhadas com os colegas de outras unidades, mas também preparei novas. Foi durante o curso que apresentamos nossas construções" (Dalvir, 20/05/2010, 23:03).

No que se refere à frequência da utilização dos softwares nas aulas de Matemática, não existe uniformidade, pois "cada professor constrói idiossincraticamente seu ideário pedagógico a partir de pressupostos teóricos e de sua reflexão sobre a prática" (FIORENTINI, 1995, p.3). Percebemos que alguns docentes procuram utilizar com certa regularidade, como Anderson. Mauro, por sua vez, comenta:

"uso geralmente quando estou trabalhando o tema sobre função, com no máximo 08 aulas. Precisamos fazer um planejamento para uso (que deve constar no quinzenário), que nada mais é do que um material que deve constar tudo que trabalhamos com nossos alunos, que consta dos seguintes elementos: objetivo, conteúdo, estratégias/metodologias, recurso e avaliação". (16/6/2010, 12:14)

No que se refere à atitude dos alunos com relação à utilização dos softwares, o professor diz que "eles cobram de nós o Winplot quinzenalmente, mesmo nos anos anteriores, em 2008 e 2009", deixando clara a aceitação da utilização dos softwares por seus alunos (Anderson, 10/05/2010, 3:39).

A mudança na prática pedagógica tem como eixo central a transformação qualitativa das ações desencadeadas pelos docentes, ainda que não tenham reflexo imediato no ensino e aprendizagem da Matemática (FIORENTINI, 1995). Há docentes que utilizaram os softwares no desenvolvimento de outras disciplinas, como vemos na fala do professor Lucas, que leciona Matemática e Física: "no momento ela é definida um vez por bimestre, pois, na Física, utilizamos o Winplot para investigar as relações das grandezas" (29/05/2010, 1:56). Observamos que a utilização das TIC deve integrar o saber do professor, e envolve fatores que não podem ser separados das diversas dimensões do ensino (TARDIF, 2002). 


\section{Considerações finais}

Pesquisas foram realizadas durante cursos online de formação continuada em parceria com uma rede nacional de escolas e ao final de suas edições. Resultados já foram apresentados, como a natureza colaborativa, coletiva e argumentativa da aprendizagem matemática (ZULATTO, 2007) nesse contexto. Também foram abordadas a colaboração dos participantes em Borba, Malheiros e Amaral (2011) e a possibilidade de os professores aprenderem Matemática com seus alunos em experiências como essas (BORBA; ZULATTO, 2010).

Ainda durante a oferta dos cursos, foi constatada a baixa evasão, um resultado curioso para cursos online; e, sobretudo, que os professores, durante os cursos online, utilizavam atividades, e um grande número deles fazia uso tanto do software de geometria como o de funções. Esses dois fatos nos levavam a avaliar o curso positivamente, considerando a inserção das TIC na prática profissional dos professores de Matemática. Por outro lado, todos sabemos do "efeito novidade", em que uma inovação pode ser utilizada em um primeiro momento e não ser utilizada posteriormente. Após sete anos do início desses cursos, é possível analisar essas experiências e perceber que as práticas de utilização dos softwares, que começaram durante a realização dos cursos, permanecem ainda em ações docentes.

Nossos dados não foram gerados visando um tratamento estatístico. A pesquisa qualitativa busca indícios, neste caso, apoiados, por exemplo, em entrevista, de como um processo se dá. Queremos compreender as diferentes formas como os professores fariam uso do software sem a interferência direta dos encontros online realizados com pesquisadores, e com a cobrança da rede de escolas sobre os efeitos diretos do curso.

Os dados quantitativos recolhidos em nossa pesquisa são relativizados. Vimos que há docentes que usam esporadicamente os softwares, e outros frequentemente. Não devemos interpretar os dados apresentados neste artigo apenas como indicação de que softwares estão sendo utilizados com frequência. É preciso ter uma postura crítica também, e refletir sobre os que não responderam. São 74 professores que fizeram os cursos e que ainda trabalham na rede de escolas, e, desses, 56 responderam o questionário, enquanto só 14 cederam entrevistas. Por que eles não responderam? Conjecturamos que é provável que muitos dos que não se dispuseram a conversar não estão utilizando software em suas aulas.

Temos ciência da intensificação da vida docente, e que nem sempre é possível disponibilizar tempo para uma entrevista online na agenda apertada do professor. Não sabemos, entretanto, se grande parte deles não conseguiu tempo para nos ceder uma entrevista ou se o fato de previrem que os docentes ministrantes dos cursos, dois dos autores deste artigo, estariam presentes nesta nova pesquisa sugeriria um possível constrangimento em dizer que não estavam utilizando nada do ensinado durante o curso. Reforçando essa ideia, temos o fato de que apenas um dos que aceitaram ser entrevistados disse: "não usei o software nenhuma vez, após o término do curso". É claro que em relação aos não-respondentes só podem ser levantadas conjecturas. Por outro lado, desprezá-los e considerar apenas os respondentes, apresentaria um resultado enviesado, sugerindo um falso sucesso do curso.

Vamos supor que os 18 não-respondentes não utilizaram os softwares. Sabemos, através dos questionários, que 48 o fizeram, e mais do que cinco vezes. Isso, de todo modo, indica uma inserção da TIC nas salas de aula que não deve mais ser classificada como pontual nesta rede de escolas. Se considerarmos que, apesar das boas condições dos laboratórios das 
escolas, havia dias em que o professor planejava incluir o laboratório em sua prática e que não era possível, pois, conforme a maioria das declarações dos professores, existe grande procura para agendamento dos mesmos, pode ser dito que o curso obteve resultado mesmo após o seu final, já que, atualmente, ainda há utilização regular, por parte dos professores, nos modos discutidos neste artigo. Os docentes desenvolvem suas práticas como "um processo de aprendizagem através do qual os professores retraduzem sua formação anterior e a adaptam à profissão" (TARDIF, 2002, p.181), reelaborando o conhecimento segundo a sua necessidade.

Essa retradução resultou em usos que variavam do esporádico, com uso baseado na projeção do software em telas; passando ao uso investigativo proposto no curso, onde a construção de conceitos por parte dos alunos teria início em experimentações com software (BORBA; VILLARREAL, 2005), seguida de uma etapa de síntese na qual o lápis e papel ocupam a função central; e chegando a usos inesperados, como aqueles de caráter interdisciplinar, ou, ainda, como disse um professor, "o computador permite simulações que coloca professores e alunos na condição de construtores e descobridores” (Mauro, 16/06/2010, 12:49).

Dessa forma, se considerarmos a autonomia relativa que os professores ainda têm para definir práticas no caso em questão, visto que as escolas não obrigam o uso de software, embora o incentivem, e a questão "retradução", podemos considerar que os professores que julgaram pertinente o uso de mídias digitais utilizaram um curso a distância para seu desenvolvimento profissional. Compreender de forma mais profunda como está sendo feito esse uso, implicaria visitas de campo a algumas destas escolas. Essa etapa será realizada em outro projeto de pesquisa.

\section{Agradecimentos}

Agradecemos a Aparecida S. Chiari, membro do grupo de pesquisa GPIMEM da Unesp, por sugestões e correções feitas na penúltima versão deste artigo e, também, a outros membros do GPIMEM que, em um momento preliminar, deram diversas sugestões sobre como estruturar o texto. São eles: Daise Lago, Débora Soares, Ana Paula dos Santos Malheiros, Marcus Vinicius Maltempi, Rejane Faria, Silvana Santos, Sueli Javaroni e Vinicius Marchi. 
O uso de softwares na prática profissional ...

\section{Referências}

ARAÚJO, J. L.; BORBA, M. C. Construindo pesquisas coletivamente em educação matemática. In: BORBA, M. C.; ARAÚJO, J. L. (Org.). Pesquisa qualitativa em educação matemática. Belo Horizonte: Autêntica, 2004. p. 25-45.

BAIRRAL, M. A. Dimensões de interação na formação à distância em matemática. Revista Perspectiva, Erechim, v. 27, n. 98, p. 33-42, jul. 2003.

Discurso, interação e aprendizagem matemática em ambientes virtuais a distância. Seropédica: EDUR, 2007.

BASTOS, H. P. P.; SILVA, J. M. Fatores de evasão em curso a distância: relato de pesquisa sobre evadidos do curso "Leitura instrumental em inglês a distância" no IFF, RJ. Revista Novas Tecnologias na Educação, Porto Alegre, v. 7, n. 3, p. 1-9, dez. 2009.

BENEDETTT, F. C. Funções, software gráfico e coletivos pensantes. 2003. 316 f. Dissertação (Mestrado em Educação Matemática) - Instituto de Geociências e Ciências Exatas, Universidade Estadual Paulista, Rio Claro, 2003.

BOGDAN, R. C.; BIKLEN, S. K. Investigação qualitativa em educação. Porto: Porto Editora, 1994.

BORBA, M. C. Students' understanding of transformations of functions using multi-representational software. 1993. Thesis (PhD in Mathematical Education) Cornell University, Ithaca, 1993.

Funções, representações múltiplas e visualização na educação matemática. In:

SEMINÁRIO INTERNACIONAL DE EDUCAÇÃO MATEMÁTICA, 1., Rio de Janeiro, 1995. Anais...Rio de Janeiro: UFRJ, 1995. p. 71-90.

BORBA, M. C.; AMARAL, R. B. A model to teach teachers to become online teachers. In: CONFERENCE OF THE INTERNATIONAL GROUP FOR THE PSYCHOLOGY OF MATHEMATICS EDUCATION, 35., Ankara, 2011. Proceedings... Ankara, 2011. v. 1. p. 262.

BORBA, M. C.; MALHEIROS, A. P. S.; AMARAL, R. B. Educação a distância online. 3. ed. Belo Horizonte: Autêntica, 2011.

BORBA, M. C.; MALTEMPI, M. V.; MALHEIROS, A. P. S. Internet avançada e educação matemática: novos desafios para o ensino e aprendizagem on-line. Novas Tecnologias na Educação, Porto Alegre, v. 3, n. 1, p. 1-10, 2005. Disponível em: <http://seer.ufrgs.br/ renote/article/view/13788/7977>. Acesso em: 20 jun. 2010.

BORBA, M. C.; ZULATTO, R. B. A. Dialogical education and learning mathematics online from teachers. In: LEIKIN, R.; ZAZKIS, R. (Ed.). Learning through teaching mathematics: development of teacher's knowledge and expertise in practice. Dordrecht: Springer, 2010. p. 111-125. (Mathematics teacher education, v. 5, part 2). 
Sant'Ana, C. C.; Amaral, R. B.; Borba, M. C.

BORBA, M. C.; VILLARREAL, M. E. Humans-with-media and the reorganization of mathematical thinking: information and communication technologies, modeling, experimentation and visualization. New York: Springer, 2005. (Mathematics education library, 39).

CANNONE, G.; ROBAYNA, M. S.; MEDINA, M. M. P. O ensino da matemática e as novas tecnologias da informação e da comunicação (TIC): estudo de caso de um grupo professores de ensino fundamental, ciclo I, em Tenerife - Espanha. Zetetiké, Campinas, v. 16. n. 30, p. 107-138, 2008.

CARBONELL, J. A aventura de inovar: a mudança na escola. Porto Alegre: Artmed, 2002.

CARNEIRO, R. F.; PASSOS, C. L. B. Vivências de professores de matemática em início de carreira na utilização das tecnologias da informação e comunicação. Zetetiké, Campinas, v. 17, n. 32, p. 101-134, 2009.

CLARK-WILSON, A. C. Approaches to in-service teacher development in England and Wales concerning the use of technology in secondary mathematics. Teaching

Mathematics and Its Applications, Oxford, v. 28, n. 4, p. 208-211, 2009.

DENZIN, N. K.; LINCOLN, Y. S. The discipline and practice of qualitative research. In: DENZIN, N.; LINCOLN, Y. S. Handbook of qualitative research. 2nd. ed. London: Sage, 2000. p. 1-32.

FAVERO, R. V. M.; FRANCO, S. R. K. Um estudo sobre a permanência e a evasão na educação a distância. Novas Tecnologias na Educação, Porto Alegre, v. 4, n. 2, p. 1-10, 2006.

FIORENTINI, D. Alguns modos de ver e conceber o ensino da matemática no Brasil. Zetetiké, Campinas, v. 3, n. 4, p. 1-38, 1995.

FIORENTINI, D.; LORENZATO, S. Investigação em educação matemática: percursos teóricos e metodológicos. Campinas: Autores Associados, 2006.

GABINI, W.S.; DINIZ, R.E.S. Os professores de química e o uso do computador em sala de aula: discussão de um processo de formação continuada. Ciência \& Educação, Bauru, v. 15, n. 2, p. 343-58, 2009.

GADANIDIS, G.; GEIGER, V. A social perspective on technology-enhanced mathematical learning: from collaboration to performance. ZDM, Eggenstein-Leopoldshafen, v. 42, n. 1, p. 91-104, 2010.

GADANIDIS, G.; NAMUKASA, I.; MOGHADDAM, A. Matemática-para-professores online: facilitando mudanças conceituais nas visões sobre matemática de professores do ensino elementar. Bolema, Rio Claro, v. 21, n. 29, p. 131-155, 2008.

GONÇALVES JÚNIOR, M. A.; BURIASCO, R. L. C. O professor de matemática e a produção de saberes sobre a gestão curricular. Ciência \& Educação, Bauru, v. 12, n. 1, p. 99-115, 2006. 
O uso de softwares na prática profissional ...

GRACIAS, T. A. S. A natureza da reorganização do pensamento em um curso a distância sobre tendências em educação matemática. 2003. 167 f. Tese (Doutorado em Educação Matemática) - Instituto de Geociências e Ciências Exatas, Universidade Estadual Paulista, Rio Claro, 2003.

KENSKI, V. M. Gestão e uso das mídias em projetos de educação a distância. Revista eCurriculum, São Paulo, v. 1, n. 1, p. 1-20, 2005-2006.

Educação e tecnologias: o novo ritmo da informação. Campinas: Papirus, 2007.

LINCOLN, Y. S.; GUBA, E. G. Naturalistic inquiry. Newbury Park: Sage, 1985.

LITTO, F. M.; FORMIGA, M. Educação a distância: o estado da arte. São Paulo: Pearson Education do Brasil, 2009.

MAIA, M. C.; MEIRELLES, F. S.; PELA, S. K. Análise dos índices de evasão nos cursos superiores a distância do Brasil: abril/2004. Disponível em: <http:// www.abed.org.br/congresso2004/por/htm/073-TC-C2.htm>. Acesso em: 11 set. 2010.

MIRANDA, D. F.; LAUDARES, J. B. Informatização no ensino da matemática: investindo no ambiente de aprendizagem. Zetetiké, Campinas, v. 15, n. 27, p. 71-88, 2007.

NASCIMENTO, M. I.; MONTEIRO, L. Avaliação de softwares educativos: aspectos relevantes. Revista e-Curriculum, São Paulo, v. 2, n. 2, junho de 2007.

NÓVOA, A. Formação de professores e profissão docente. In: NÓVOA, A. (Org.). Os professores e a sua formação. 2. ed. Lisboa: Dom Quixote, 1995. p.13-33.

PENTEADO, M. G. Possibilidades para a formação de professores de matemática. In: PENTEADO, M. G.; BORBA, M. B. (Org.). A informática em ação: formação de professores, pesquisa e extensão. São Paulo: Olho d'Água, 2000. p. 23-34.

PONTE, J. P. Investigar a nossa própria prática: uma estratégia de formação e de construção do conhecimento profissional. PNA, Granada, v. 2, n. 4, p. 153-180, 2008.

REZENDE, F.; LOPES, A. M. A.; EGG, J. M. Identificação de problemas do currículo, do ensino e da aprendizagem de física e de matemática a partir do discurso de professores.

Ciência \& Educação, Bauru, v. 10, n. 2, p. 185-196, 2004.

SANTOS, S. C. A produção matemática em um ambiente virtual de aprendizagem: o caso da geometria euclidiana espacial. 2006. 144 f. Dissertação (Mestrado em Educação Matemática) - Instituto de Geociências e Ciências Exatas, Universidade Estadual Paulista Júlio de Mesquita Filho, Rio Claro, 2006.

SANTOS, E. M.; OLIVEIRA NETO, J. D. Evasão na educação a distancia: identificando causas e propondo estratégias de prevenção. Paidéi@: Revista Científica de Educação a Distância, Santos, v. 2, n. 2, p. 1-28, dez. 2009.

SHULMAN, L. S. Those who understand: knowledge growth in teaching. Educational Researcher, Washington, v. 15, n. 2, p.4-14, 1986.

TARDIF, M. Saberes docentes e formação profissional. Petrópolis: Vozes, 2002. 
Sant'Ana, C. C.; Amaral, R. B.; Borba, M. C.

VIDICH, A. J.; LYMAN, S. M. Qualitative methods: their history in sociology and anthropology. In: DENZIN, N. K.; LINCOLN, I. S. (Org.). Handbook of qualitative research. 2nd. ed. London: Sage, 2000. p. 23-44.

ZULATTO, R. B. A. Professores de matemática que utilizam softwares de geometria dinâmica: suas características e perspectivas. 2002. 199 f. Dissertação (Mestrado em Educação Matemática) - Instituto de Geociências e Ciências Exatas, Universidade Estadual Paulista, Rio Claro, 2002.

A natureza da aprendizagem matemática em um ambiente online de formação continuada de professores. 2007. 174 f. Tese (Doutorado em Educação Matemática) - Instituto de Geociências e Ciências Exatas, Universidade Estadual Paulista, Rio Claro, 2007.

Artigo recebido em 03/09/2011. Aceito em 21/02/2012. 